\title{
SUSCETIBILIDADE A ESCORREGAMENTOS E INUNDAÇÕES: HIERARQUIZAÇÃO DOS GRAUS DE RISCOS NA ÁREA URBANA DE VIÇOSA-MG
}

\author{
SUSCEPTIBILITY TO SLANDSLIDES AND FLOODS: \\ HIERARCHIZATION OF RISKS DEGREES IN THE URBAN \\ AREA OF VIÇOSA-MG \\ SUSCEPTIBILIDAD A DESLIZAMIENTOS DE TIERRA Y \\ INUNDACIONES: CLASIFICACIÓN DE GRADOS DE RIESGOS \\ EN EL ÁREA URBANA DE VIÇOSA-MG
}

\author{
Cinthia Maria Amaral \\ Mestre em Geografia pela Universidade Federal Fluminense - UFF Campos. Rua José do Patrocínio, \\ 71, Centro. Campos dos Goytacazes - RJ. CEP: 28010-385. \\ E-mail: cinthiaamarall@gmail.com
}

\section{Claudio Henrique Reis}

Doutorado em Geografia pela Universidade Federal do Rio de Janeiro - UFRJ. Professor Adjunto III e Professor do Mestrado em Geografia na Universidade Federal Fluminense - UFF Campos. Rua José do Patrocinio, 71, Centro. Campos dos Goytacazes - RJ. CEP: 28010-385.

E-mail: claudioreis@id.uff.br

\section{RESUMO}

A identificação das áreas de risco é um importante instrumento para gestão das políticas públicas. Desse modo, esse trabalho objetivou hierarquizar as áreas de riscos a escorregamentos e inundações na área urbana do município de Viçosa, Minas Gerais, através de técnicas de Geotecnologias. Utilizou-se a metodologia de Álgebra de Mapas através da distribuição de ponderação para os mapas de Uso e Cobertura da Terra, Declividade e Compartimentação Geomorfológica, efetivando a soma/multiplicação desses fatores e de suas classes resultando em três graus de riscos: Grau 1 (Baixo Risco), Grau 2 (Médio Risco) e Grau 3 (Alto Risco). Assim, concluiu-se que, além das classificações de Médio e Baixo Risco, cerca de $60 \%$ da área urbana de Viçosa é considerada de Alto Risco para escorregamentos e $24 \%$ para inundações. A utilização das geotecnologias como embasamento metodológico apresentou viabilidade para planejamentos voltados a mitigação e prevenção de desastres naturais em áreas urbanas.

Palavras-chave: Áreas de Riscos; Escorregamentos; Inundações; Geotecnologias. 


\begin{abstract}
The identification of risk areas is an important tool for the management of public policies. Thus, this work aimed to hierarchize the risk areas for landslides and floods in the urban area of the municipality of Viçosa, Minas Gerais, using techniques of Geotechnology. Was used the methodology of Map Algebra through the weighting distribution for the maps of Land Use and Cover, Declivity and Geomorphological Compartmentalization, effecting the sum/multiplication of these factors and their classes resulting in three degrees of risk: Grade 1 (Low Risk), Grade 2 (Medium Risk) and Grade 3 (High Risk). Thus, it was concluded that, in addition to the Medium and Low Risk classifications, about $60 \%$ of the urban area of Viçosa is considered High Risk for landslides and 24\% for floods. The use of geotechnologies as a methodological basis presented viability for planning aimed at mitigation and prevention of natural disasters in urban areas.
\end{abstract}

Keywords: Areas of Risks; Landslides; Floods; Geotechnologies.

\title{
RESUMEN
}

La identificación de áreas de riesgo es una herramienta importante para la gestión de políticas públicas. De ese modo, este estudio tuvo como objetivo dar prioridad a las áreas de riesgo a deslizamientos de tierra e inundaciones en el área urbana de Viçosa, Minas Gerais, con técnicas de Geotecnologías. Se utilizó la metodología de Álgebra de mapas mediante la distribución de peso a los mapas de uso y cobertura de la tierra, la declividad y la compartimentación geomorfológica, efectuando la adición/ multiplicación de estos factores y sus clases resultantes en tres grados de riesgo: Grado 1 ( Bajo Riesgo), Grado 2 (Medio Riesgo) y Grado 3 (Alto Riesgo). Por lo tanto, se concluyó que, además de las clasificaciones de Riesgo Medio y Bajo, alrededor del 60\% del área urbana de Viçosa se considera Alto Riesgo de deslizamientos de tierra y 24\% para las inundaciones. El uso de geotecnología como base metodológica, más allá de bajo costo, presentó factibilidad a los planes dirigidos a la mitigación y prevención de desastres naturales en las áreas urbanas.

Palabras-Clave: Áreas de Riesgos; Deslizamientos de Tierra; Inundaciones; Geotecnologías. 


\section{INTRODUÇÃO}

Através das intensas transformações e inadequado uso da terra sofridos ao longo dos anos, que somados ao crescimento populacional demasiado, o espaço urbano resulta nas potencialidades de degradações dos condicionantes naturais que podem ser agravados com a atuação e interferência antropogênica (GONÇALVES; GUERRA, 2009; GUIMARÃES et al., 2008).

Processos físicos de diferentes magnitudes sempre aconteceram independentes da ação do homem, pois fazem parte da dinâmica natural da Terra podendo ser de origem interna (terremotos, erupções vulcânicas etc.) ou externa (escorregamentos, secas, inundações dentre outros tipos) (SAITO; SORIANO; LONDE, 2015).

Os movimentos de massa, sobretudo os escorregamentos, e as inundações são os processos naturais que mais ocorrem em áreas urbanas de climas tropicais. As intervenções antrópicas nessas áreas, como as habitações em encostas e em fundos de vale, ausentes de técnicas adequadas, têm acarretado em significativas alterações na paisagem, como a intensificação e/ou aceleração desses processos (GONÇALVES; GUERRA, 2009). Essas interferências realizadas sobre a encosta poderão afetar as formas do relevo e os processos operantes a depender do local de atuação e do material constituinte e dependendo, também, de sua escala, poderão gerar consequências catastróficas (AMARAL, 2013).

Os movimentos de massa se caracterizam como o transporte coletivo de material rochoso e/ou de solo, onde a ação da gravidade tem função principal, podendo ser ou não potencializado pela ação da água (GUERRA; MARÇAL, 2015). Dentre os tipos existentes, os escorregamentos (slides) estão mais presentes em áreas urbanas e caracterizam-se como movimentos rápidos de curta duração e com plano de ruptura bem definido. São feições longas e podem ser divididos em rotacionais e translacionais (FERNANDES; AMARAL, 2009). Estes movimentos, quando intensificados ou potencializados pelo homem, podem ser vistos como respostas das encostas a perturbações das relações entre a natureza e a antropização inadequada (JORGE; GUERRA, 2013).

Devido à alta capacidade de utilização dos rios (transporte, consumo, descarte de dejetos, etc.), principalmente nas áreas urbanas, o processo de ocupação se orientou a partir dos cursos d'água, em áreas mais planas e declividades amenas (TUCCI, 2007) ramificandose para as encostas quando essas áreas encontravam-se demasiadamente ocupadas. 
As inundações ocorrem a partir do momento em que as águas transbordam, ultrapassando a cota e atingindo o leito maior (GOERL; KOBIYAMA, 2005). Esse processo pode ocorrer devido a intensa precipitação e onde o solo não tem capacidade de infiltração, com alta impermeabilidade escoando assim, parte do volume para o sistema de drenagem para além da capacidade do leito menor (TUCCI, 2007).

Dos tipos de inundações existentes, a gradual e a brusca são as mais ocorrentes em áreas urbanas e estão infimamente relacionadas a velocidade do acontecimento do evento com a duração do mesmo (minuto(s)/hora(s)/dia(s)) (KOBIYAMA et al., 2006.; GOERL; KOBIYAMA, 2005).

Atuando de forma significativa como agente modificador artificial do relevo, as ocupações em áreas de riscos vêm acelerando e/ou potencializando os processos naturais. Ademais, a criação de encostas artificiais (retirada do sopé, construção de rodovias, aplainamentos etc.), interfere diretamente no equilíbrio e evolução natural das encostas (GUERRA; MARÇAL, 2015).

Área de risco, portanto, é aquela passível de ser atingida por fenômenos, processos naturais e/ou induzidos. As pessoas que ocupam essas áreas estão mais vulneráveis a danos de integridade física, perdas materiais e patrimoniais. Comumente, no contexto dos centros urbanos brasileiros, essas áreas correspondem a núcleos habitacionais de baixo poder aquisitivo (MINISTÉRIO DAS CIDADES - IPT, 2007).

Os elementos alinhados ao risco, sociedade e/ou estruturas físicas, podem estar relacionados ao mesmo perigo e ameaça, porém em diferentes escalas e maneiras. Essa não é uma condição associada somente a categorias econômicas, mas também ligados a fatores históricos, culturais e socioambientais desses elementos (SAITO; SORIANO; LONDE, 2015).

Assim, entende-se que os desastres naturais podem ser desencadeados por processos que envolvem variáveis físicas (relevo, vegetação, rios, precipitação, entre outras) e/ou humanas (população, ocupação da terra, atividades econômicas, educação, etc.) (MARCELINO et al., 2006, apud SAITO; SORIANO; LONDE, 2015). A potencialidade de ocorrência desses processos, naturais e/ou induzidos, indica a suscetibilidade de determinada área que podem se expressar, por exemplo, segundo classes de probabilidade de ocorrência (MINISTÉRIO DAS CIDADES - IPT, 2007).

Essa questão vem ganhando destaque e importância nos estudos geomorfológicos e geográficos nos últimos anos, sobretudo para ambientes demasiadamente antropomorfizados 
nas áreas urbanas. A utilização das técnicas de geotecnologias corrobora para um melhor diagnóstico e análise dos riscos. O emprego de imagens de satélite e radar somados aos trabalhos de campo é inerente para promover maior agilidade nos resultados e estes apresentarem melhor qualidade de acordo com cada especificidade.

Desse modo, essa pesquisa teve por objetivo hierarquizar os graus de riscos a escorregamentos e inundações na área urbana do município de Viçosa, Minas Gerais, através de técnicas de geotecnologias. Esse estudo foi embasamento teórico-metodológico que identificou e classificou, posteriormente, os grupos de vulnerabilidade social para cada tipo de risco nessas áreas.

\section{MATERIAIS E MÉTODOS}

\section{Breve caracterização da área de estudo}

O município de Viçosa, com área total de 299,41 Km² e população de 72220 mil habitantes (IBGE, 2010), está inserido na porção noroeste da Zona da Mata de Minas Gerais, entre as coordenadas geográficas de $20^{\circ} 45^{\prime} 14^{\prime \prime}$ de latitude Sul e $42^{\circ} 52^{\prime} 54^{\prime \prime}$ de longitude Oeste (PREFEITURA DE VIÇOSA, 2016) (Figura 1).

Figura 1. Localização da área de estudo: área urbana do município de Viçosa-MG

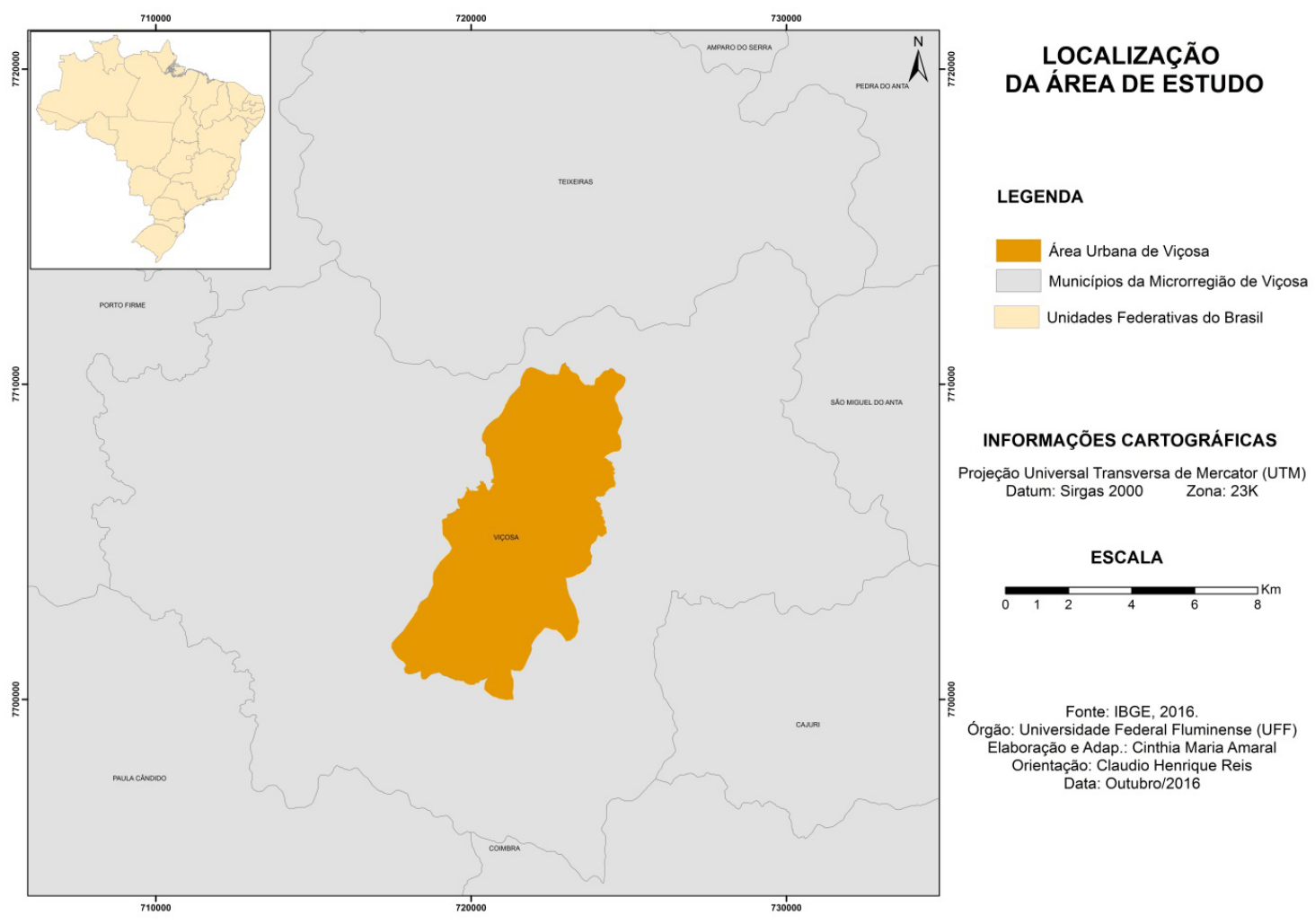

Fonte: Adaptado de Amaral, 2017. 
A área urbana do município de Viçosa compreende $41,98 \mathrm{Km}^{2}$ e foi delimitada, para essa pesquisa, através dos limites territoriais dos setores censitários urbanos elaborados pelo Instituto Brasileiro de Geografia e Estatística (IBGE), não sendo incluídos, porém, os distritos de São José do Triunfo e Cachoeira de Santa Cruz.

O município compreende o Domínio Morfoclimático de Mares de Morros, com clima classificado em tropical de altitude (VALVERDE, 1958) apresentando um período de chuvas acentuadas e temperaturas mais elevadas e outro com baixos índices pluviométricos e temperaturas mais amenas (BATISTA; RODRIGUES, 2010). No que tange a hidrografia, o município está inserido na bacia hidrográfica do rio Doce e em sítio urbano é drenado pelo rio Turvo Sujo e, principalmente, pelo ribeirão São Bartolomeu que intercepta a área urbana central (ROQUE, 2013). Nas encostas são encontrados solos do tipo Latossolos e, nos fundos de vale, são identificados solos do tipo Neossolos associados aos Vertissolos e, nos terraços, são encontrados Argissolos (CARNEIRO; FARIA, 2005; REZENDE, 1971). A cobertura vegetal consta de remanescentes secundários de Floresta Estacional Semidecidual, do bioma Mata Atlântica (AGUIAR; TEIXEIRA, 2015).

\section{Procedimentos metodológicos}

Para o embasamento equacional, utilizou-se ponderação para os mapas de Uso e Cobertura da Terra, Declividade e Compartimentação Geomorfológica para ser aplicada na metodologia de Álgebra de Mapas que, de acordo com Tomlin (1990 apud Cordeiro; Barbosa; Câmara, 2001), consiste na associação que o mapa faz a cada local de uma dada área de estudo, seja em valor quantitativo ou qualitativo.

Para elaboração dos mapas base foram utilizadas imagens de satélite RapidEye, com passagem em 02 de agosto de 2014, imagem de radar do projeto TOPODATA/SRTM, dados em formatos shapefile (divisão territorial, setores censitários, etc.) e cartas topográficas (1:50 000) folhas de Teixeiras e Viçosa, extraídos e cedidos para download no Ministério do Meio Ambiente (MMA), Instituto Nacional de Pesquisas Espaciais (INPE), Instituto Brasileiro de Geografia e Estatística (IBGE) e no Banco de Dados Geográficos do Exército (BDGEx), respectivamente.

Em ambiente de geoprocessamento foram utilizados os softwares Spring 5.4.1 (desenvolvido pelo Instituto Nacional de Pesquisas Espaciais - INPE), para o mapa de Uso e Cobertura da Terra, e o ArcGIS 10.1 (desenvolvido pela Environmental Systems Research Institute - ESRI), para a elaboração dos mapas de Declividade e Compartimentação Geomorfológica. A escala cartográfica utilizada para análise foi diferenciada de acordo com os elementos e objetivos propostos: Uso e Cobertura da Terra, escala de 1: 25 000; e para 
os demais fatores, a escala cartográfica utilizada foi de 1:50 000. Para melhor visualização dos resultados obtidos, os produtos finais foram exportados em escala de 1: 40000 . Os procedimentos realizados para cada mapa citado acima estão elencados e detalhados a seguir.

\section{Uso e cobertura da terra}

Através do processamento de imagens elaborou-se o mapa de Uso e Cobertura da Terra. Após ser feito o carregamento de cena com as bandas 3, 4 e 5, no sistema RGB em falsacor da RapidEye, seguiu-se para os passos de realce do contraste da imagem, segmentação e a classificação por regiões.

A finalidade das técnicas do realce é facilitar a interpretação da imagem, aprimorando a qualidade da mesma e permitindo melhor entendimento e descrição dos objetos presentes (DPI - INPE, 2015; FLORENZANO, 2008).

A segmentação de imagens é um procedimento computacional que permite a divisão da imagem em regiões espectralmente homogêneas (FLORENZANO, 2008), definindo valores referentes à limiares de similaridade e de área, que para esse trabalho foi de $200 \mathrm{e}$ 300, respectivamente.

Por fim, foi concretizado o procedimento de classificação por regiões, no caso a Bhattacharya, que segundo Santos et al. (2010), requer a seleção de áreas de treinamento, podendo utilizar as regiões separadas durante o processo de segmentação ou polígonos representativos das regiões a serem classificadas. O procedimento de treinamento, onde há escolha e nomeação das classes, repete-se no momento de pós-classificação.

O tamanho da área urbana $\left(41,98 \mathrm{Km}^{2}\right)$ facilita o nível de detalhamento em comparação a área total do município $\left(299,41 \mathrm{Km}^{2}\right)$. Além do mais, a imagem do sensor RapidEye possui resolução espacial de 5 metros, o que permitiu estabelecer subclasses para algumas classes, ficando assim definidas: Área Urbana (Área Urbana de Alta Densidade (UrbAD), Área Urbana de Média Densidade (UrbMD) e Área Urbana de Baixa Densidade (UrbBD), Mata Secundária (Mata Secundária Regenerada (MSecReg) e Mata Secundária em Regeneração (MSecemReg), Cultura (Café e Eucalipto), Drenagem, Pastagem, Solo Exposto.

\section{Declividade e compartimentação geomorfológica}

A imagem TOPODATA/SRTM que é cedida para download pelo INPE tem resolução espacial de 30 metros, resolução radiométrica de 32 bits e escala de 1:250 000, foi inserida no software ArcGIS 10.1 para concretizar os procedimentos a seguir. Essa imagem é operante na faixa de micro-ondas, ou seja, fora da faixa do visível e infravermelho, e o seu modo 
de visualização só é permitido em pancromático (em níveis de cinza) (ROSA, 2009). Foi necessário, para melhores resultados, conversão para 16 bits inteiro não sinalizado, realizar a referência espacial e a reprojeção para um sistema de coordenas planas (UTM), neste caso inserido o Datum SIRGAS 2000 UTM Zona 23S, o mesmo adotado para todos os mapas elaborados nesse estudo.

Para o mapa de declividade extraiu-se as curvas de nível com equidistância de 5 metros da imagem do produto TOPODATA/SRTM. Após esse procedimento, a declividade foi definida em porcentagem, onde as escolhas dos intervalos se deram para cumprir com os objetivos aqui propostos e para auxiliar na metodologia de compartimentação geomorfológica do IPT (1981). Levou-se em consideração também, a declividade e os riscos que a ela estão ligados, como as áreas com declividade inferior a $2 \%$ que são suscetíveis a inundação (SILVEIRA; CUNHA, 2006), por exemplo. As classes ficaram definidas em Muito Baixa, Baixa, Mediana, Alta e Muito Alta, sendo a porcentagem (\%) representada nos intervalos: menor que 2,2 a 7,7 a 15, 15 a 30 e maior que 30 , respectivamente.

Para realizar a compartimentação geomorfológica adicionou-se a essa pesquisa a metodologia do IPT (1981), que se fundamenta nos critérios morfométricos de declividade e amplitude altimétrica para definir tal compartimentação (TORRES; MARQUES NETO; MENEZES, 2012). Objetivou-se, portanto, chegar ao $4^{\circ}$ táxon proposto por Ross (1992), estabelecido como Formas de Relevo, que são compostos pelos modelados de Agradação (A) e Degradação (D). Assim, os modelados Agradacionais foram identificados através das curvas de nível extraídas (50 metros), cartas topográficas (1: 50 000) e metodologia de interpretação visual de dados (ROSA, 2009), com imagens do Google Earth. Já os modelados Degradacionais foram estabelecidos conforme critérios morfométricos onde são identificados: os intervalos de declividade de 0 a 15\%, com amplitude menor que 100 metros para relevo colinoso e de 100 a 300 metros para relevo de morros com encostas suavizadas e, para os intervalos de declividade superiores a 15\%, a amplitude menor que 100 metros se remetem a morrotes e de 100 a 300 metros a relevo de morros (IPT, 1981).

Devido a inviabilidade de algumas áreas para com a escala de análise utilizada, ressaltase que algumas formas de relevo foram identificadas e reconhecidas em campo, mesmo se observando alterações significativas na sua gênese devido a atuação antrópica in loco.

\section{Hierarquização dos riscos a escorregamentos e inundações}

Após confecção e verificação dos resultados dos mapas, foi estabelecida ponderação para os fatores de Uso e Cobertura da Terra, Declividade e Compartimentação Geomorfológica e para suas classes/intervalos. Desse modo, para a ponderação dos fatores estabeleceu- 
se pesos cujo intervalo teve variação de 0 a 1 e, para as classes/intervalos, os pesos foram distribuídos no intervalo de 1 a 5, de forma que ambas as ponderações tivessem correlação e importância frente aos riscos aqui em questão (Tabela 1). Devido ao software não aceitar números fracionados para cálculos de raster, estabeleceu as junções das subclasses UrbAD, UrbMD e UrbBD para Área Urbana, MSecReg e MSecemReg para Mata Secundária, e Café e Eucalipto para Cultura.

Tabela 1. Distribuição da ponderação para os fatores e suas classes /intervalos

\begin{tabular}{|c|c|c|c|c|}
\hline \multirow[t]{4}{*}{ Fatores } & Ponderação/Fator & Classes & Escorregamento & Inundação \\
\hline & & Drenagem & 1 & 5 \\
\hline & & Área Urbana & 4 & 4 \\
\hline & & $\begin{array}{c}\text { Mata } \\
\text { Secundária }\end{array}$ & 2 & 1 \\
\hline \multirow[t]{5}{*}{$\begin{array}{c}\text { Uso e Cobertura } \\
\text { da Terra }\end{array}$} & $\begin{array}{l}0.20 \text { (escorregamentos) } \\
\text { e } 0.25 \text { (inundação) }\end{array}$ & Cultura & 2 & 2 \\
\hline & & Pastagem & 3 & 2 \\
\hline & & Solo Exposto & 5 & 3 \\
\hline & & $<2$ & 1 & 5 \\
\hline & & $2-7$ & 2 & 4 \\
\hline \multirow[t]{6}{*}{ Declividade (\%) } & $\begin{array}{c}0.10 \text { (escorregamento e } \\
\text { inundação) }\end{array}$ & $7-15$ & 3 & 3 \\
\hline & & $15-30$ & 4 & 2 \\
\hline & & $>30$ & 5 & 1 \\
\hline & & Planície Fluvial & 1 & 5 \\
\hline & & Terraço Fluvial & 2 & 4 \\
\hline & & $\begin{array}{c}\text { Rampas de } \\
\text { Colúvio }\end{array}$ & 2 & 3 \\
\hline \multirow[t]{4}{*}{$\begin{array}{c}\text { Compartimentação } \\
\text { Geomorfológica }\end{array}$} & $\begin{array}{c}0.30 \text { (escorregamento e } \\
\text { inundação) }\end{array}$ & Colinas & 3 & 2 \\
\hline & & $\begin{array}{c}\text { Morros com } \\
\text { encostas } \\
\text { suavizadas }\end{array}$ & 3 & 2 \\
\hline & & Morrotes & 4 & 1 \\
\hline & & Morros & 5 & 1 \\
\hline
\end{tabular}

Fonte: Adaptado de Amaral, 2017. 
Foram criadas duas equações para aplicação na Álgebra de Mapas, onde a primeira (E1) se efetivou na soma simples dos fatores e classes/resultados e a segunda (E2), na soma dos fatores multiplicando-os com a valoração correspondente aplicada, ficando assim representadas:

E1: Uso e Cobertura da Terra + Declividade + Compartimentação Geomorfológica = Hierarquização de Riscos

E2: Uso e Cobertura da Terra * (peso) + Declividade * (peso) + Compartimentação Geomorfológica * $($ peso $)=$ Hierarquização de Riscos

A finalidade de efetuar duas equações foi observar se houve interferência quando se estabelece pesos para os fatores e para suas classes/intervalos, realizando soma simples ou soma e multiplicação e pronunciando a maior ou menor importância de cada fator frente aos riscos apontados. O produto final de áreas de riscos a escorregamentos e inundações foi elaborado através de uma hierarquização de graus, estipulados de 1 a 3, onde quanto maior o grau, maior o risco.

Após os procedimentos de gabinete, os trabalhos de campo foram realizados a fim de verificar os resultados obtidos e compará-los com a realidade local. Assim, houve o reconhecimento das áreas e do tipo de ocupação, da maior incidência de escorregamentos e inundações e da compartimentação geomorfológica, além de ter facilitado a identificação destas, e também a verificação de todos os resultados obtidos na classificação digital.

\section{RESULTADOS E DISCUSSÃO}

A classificação do Uso e Cobertura da Terra elaborada a partir da imagem do sensor RapidEye (Figura 2), propiciou resultados mais apurados devido a maior resolução espacial que essa imagem possui, pois, conforme explicado anteriormente, o sistema de classificação definido para o de Uso e Cobertura da Terra admitiu, para as classes de Área Urbana, Mata Secundária e Cultura, identificação de subclasses.

Assim, sobre a Área Urbana, a UrbMD apresenta maior área (9,20\%), seguida pela UrbAD (7,15\%) e UrbBD (6,55\%). Para a Mata Secundária, a MSecReg e a MSecemReg representam juntas $36 \%$ de área verde significativa dentro da área urbana. A identificação dos cultivos de Café e Eucalipto foram concretizados através da configuração geométrica de cada um e, juntos, representam cerca de 3,5\% da área de estudo. 
Figura 2. Resultado do Uso e Cobertura da Terra na área urbana de Viçosa-MG.

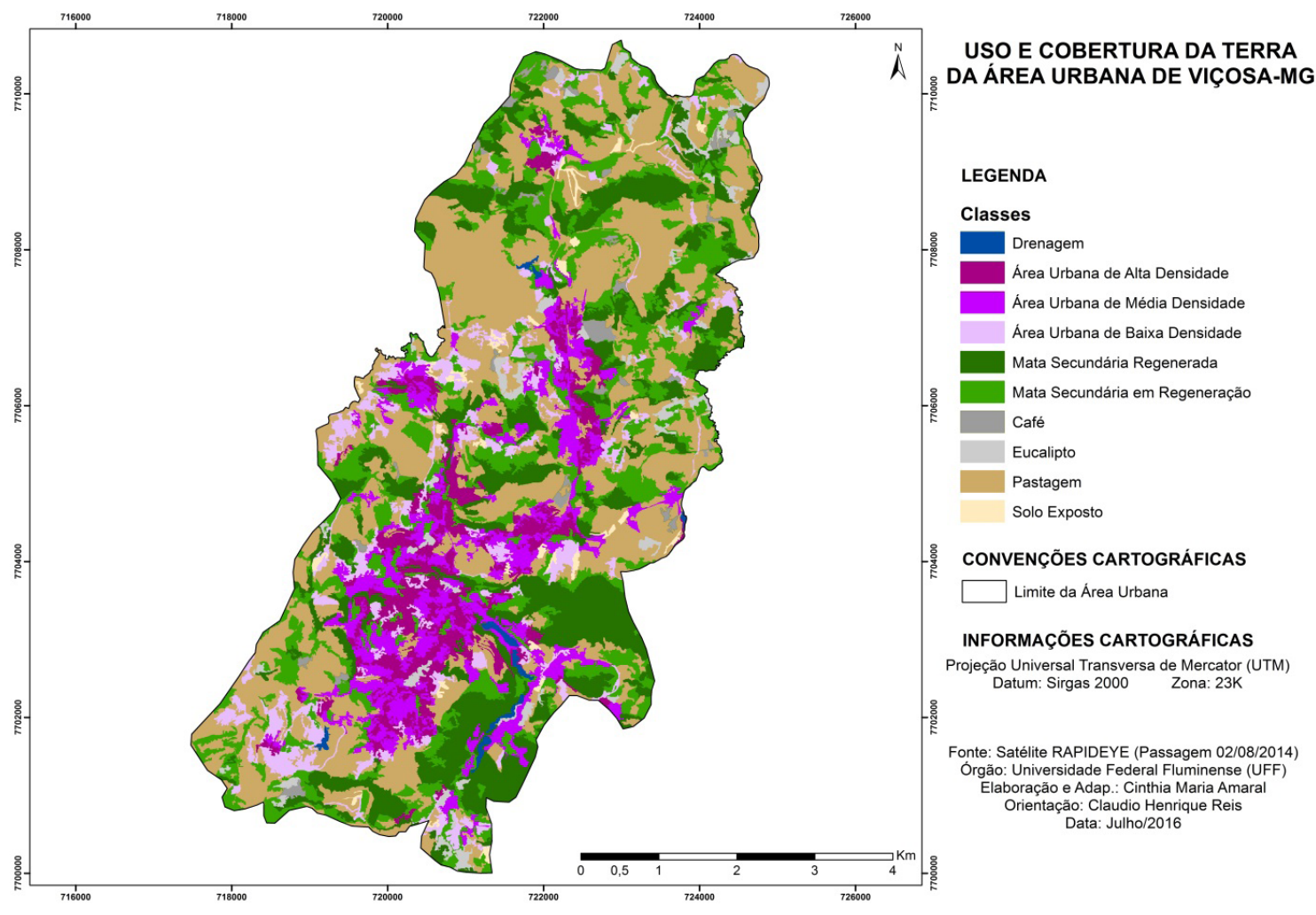

Fonte: Adaptado de Amaral, 2017.

Em relação às outras classes, a pastagem detém maior parcela territorial com 35,45\%, mesmo que em área urbana. A menor área representada é da drenagem com 0,45\%, justificada pela não classificação de outros cursos d'água que são de menos expressivos frente ao tamanho da área. Por fim, 0,90\% representam os Solos Expostos. A Tabela 2 mostra, em área e porcentagem, a representatividade de cada classe e subclasse identificadas e classificadas. 
Tabela 2. Cálculo de área $\left(\mathrm{Km}^{2}\right)$ das classes/subclasses da imagem do sensor RapidEye

\begin{tabular}{lcccc}
\multicolumn{1}{c|}{ Classes } & Subclasses & Área ( $\mathbf{K m}^{\mathbf{2}} \mathbf{)}$ & Área (\%) \\
\hline Drenagem & - & 0,19 & 0,45 \\
\hline Área Urbana & UrbAD & 3,00 & 7,15 \\
\hline Área Urbana & UrbMD & 3,86 & 9,2 \\
\hline Área Urbana & UrbBD & 2,75 & 6,55 \\
\hline Mata Secundária & MSecReg & 7,38 & 17,58 \\
\hline Mata Secundária & MSecemReg & 8,00 & 19,06 \\
\hline Cultura & Café & 0,56 & 1,33 \\
\hline Cultura & Eucalipto & 0,98 & 2,33 \\
\hline Pastagem & - & 14,88 & 35,45 \\
\hline Solo Exposto & - & 0,38 & 0,9 \\
\hline Área total das classes & - & 41,98 & 100 \\
\hline Área total dos polígonos não classificados & - & 0 & 0 \\
\hline
\end{tabular}

Fonte: Adaptado de Amaral, 2017.

De acordo com os resultados de Declividade e Compartimentação Geomorfológica (Figuras 3 e 4, respectivamente), mais da metade dessa área é composta por morros que se orientam com declividades que podem ser superior a $30 \%$.

Figura 3. Resultado dos intervalos de declividade da área urbana de Viçosa-MG

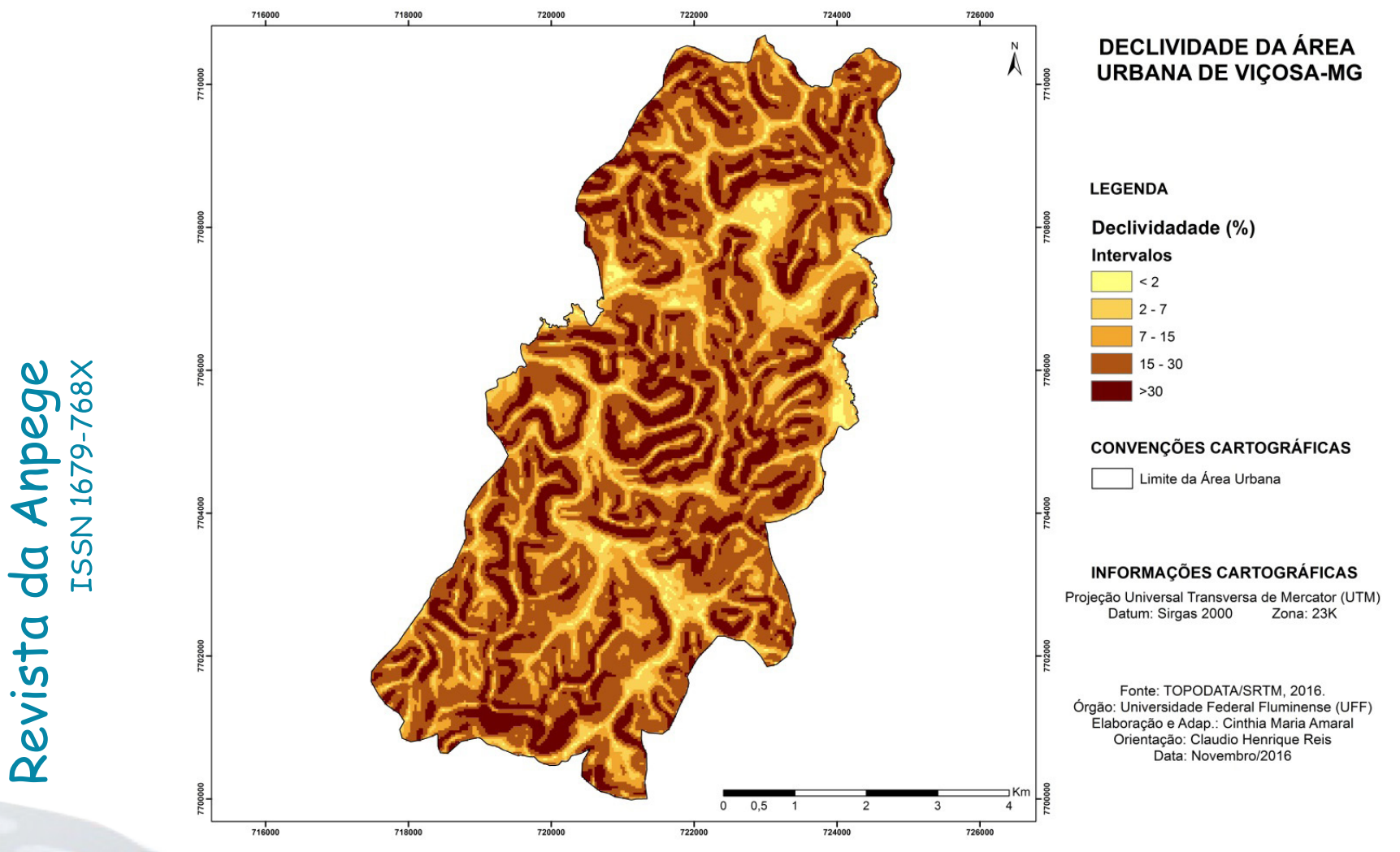

a Fonte: Adaptado de Amaral, 2017. 
Os morrotes também foram identificados em frequência considerada e detêm declividade nos intervalos de 15 a 30\%, geralmente. As áreas menos declivosas (inferior a 15\%), são constituídas de planícies e terraços fluviais, rampas de colúvio e colinas. A área urbana do município de Viçosa constitui-se de fatores físicos que somados a ação humana inadequada, favorecem e/ou agravam a ocorrência e frequência dos processos de escorregamentos e inundações.

Figura 4. Resultado da compartimentação geomorfológica da área urbana de Viçosa-MG

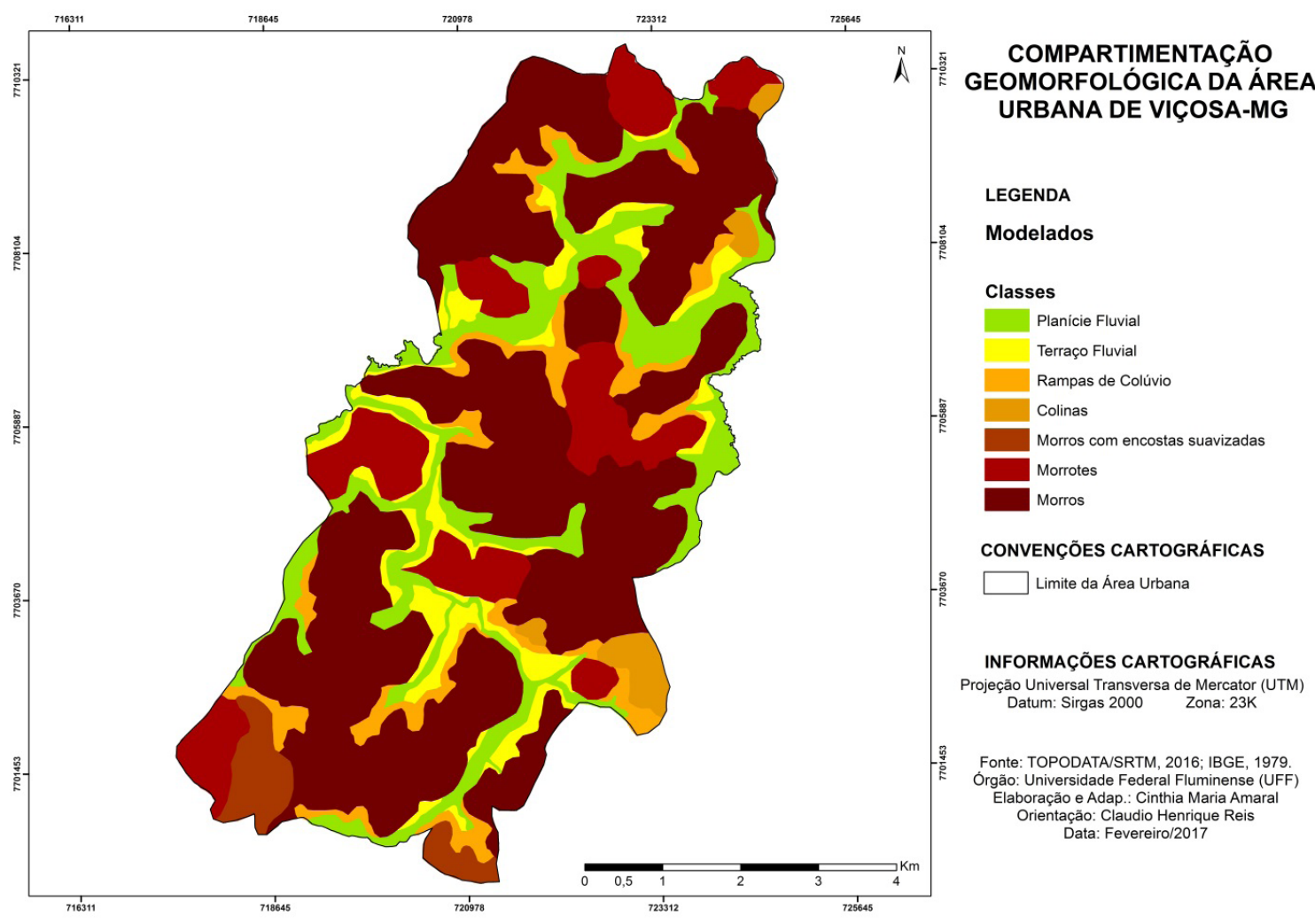

Fonte: Adaptado de Amaral, 2017.

As planícies se estabelecem, comumente, em declividades inferiores a 2\%, áreas estas suscetíveis a inundações (SILVEIRA; CUNHA, 2006). Os terraços, que são áreas de acumulações, planas e levemente inclinadas e, as rampas de colúvio, que são originadas a partir de processos de dissecação (IBGE, 2009), começam a se configurar com declividade mais elevada. As colinas e morros com encostas suavizadas possuem declives menores que $15 \%$ e se diferenciam pela amplitude do relevo local, sendo menor que 100 metros para as colinas e entre 100 a 300 metros para os morros suavizados. Na área urbana do município de Viçosa predominam-se as declividades superiores a 15\% e mais da metade é constituído por formação de morros. 
A sintetização dos resultados dos mapas de Uso e Cobertura da Terra, Declividade e Compartimentação Geomorfológica objetivou caracterizar de forma aproximada, a morfologia do relevo urbano do município. A aplicação da metodologia de Álgebra de Mapas permitiu, através de duas equações, chegar a dois resultados distintos para cada fator (risco a escorregamentos e risco a inundações) e a análise e escolha da equação ideal para essa metodologia está descrita a seguir.

Áreas suscetíveis a escorregamentos e inundações: hierarquização dos riscos

A aplicação da equação 2 (E2) para identificação das áreas de risco a escorregamentos e inundações se mostrou mais viável e compatível, principalmente no que diz respeito à detecção das áreas de maior grau de risco, apresentando resultados mais homogêneos entre os graus de hierarquização, facilitando identificar os graus de risco 1 (baixo), 2 (médio) ou 3 (alto) nos setores censitários.

Na análise da equação 1 (E1), as áreas detectadas de maior grau se mescla às informações de graus inferiores, dificultando o apontamento das áreas (setores) de maior risco. Para os riscos de inundação, por exemplo, as áreas de alto e médio risco foram expandidas para áreas que são, de fato, de baixo grau. Em relação aos resultados quantitativos, a Tabela 3 mostra a diferença em área/quilômetro para cada grau gerado e para cada risco elencado.

Tabela 3. Resultado em área para riscos a escorregamentos e inundações e para a vulnerabilidade social com aplicação da E1 e E2.

\begin{tabular}{c|c|c|c} 
Fatores & Risco & $\begin{array}{c}\text { E1 - Área }\left(\mathbf{K m}^{\mathbf{2}}\right) \\
\text { (Absoluto) }\end{array}$ & $\begin{array}{c}\text { E2 - Área }\left(\mathbf{K m}^{\mathbf{2}}\right) \\
\text { (Absoluto) }\end{array}$ \\
\cline { 2 - 4 } Escorregamentos & 1 & 10,36 & 8,79 \\
\cline { 2 - 4 } & 2 & 15,7 & 6,89 \\
\cline { 2 - 4 } & 3 & 15,53 & 25,9 \\
\hline \multirow{3}{*}{ Inundações } & 1 & 18,78 & 21,06 \\
\cline { 2 - 4 } & 2 & 12,48 & 10,5 \\
\hline Total Área Urbana & - & 10,33 & 10,03 \\
\hline Total Área por Fator & - & 41,98 & 41,98 \\
\hline Área não-classificada & - & 41,59 & 41,59 \\
\hline
\end{tabular}

Fonte: Adaptado de Amaral, 2017.

As Figuras 5 e 6 representam, respectivamente, os resultados das equações 1 e 2 para hierarquização dos riscos a escorregamentos e inundações. A comparação visual se faz necessária para justificativa da escolha da E2 como resultado satisfatório e que permitirá analisar esses riscos na área urbana do município. 
Os resultados da equação 2 (E2) somado a análise dos mapas base (Uso e Cobertura da Terra, Declividade e Compartimentação Geomorfológica) permitiram fazer uma breve descrição das características de cada grau de risco para cada fator. Essas características sintetizam cada grau de risco, sempre observados e direcionados aos fatores aqui mencionados.

Figura 5. Resultados da hierarquização de risco a escorregamentos com aplicação da equação 1 e 2, respectivamente.

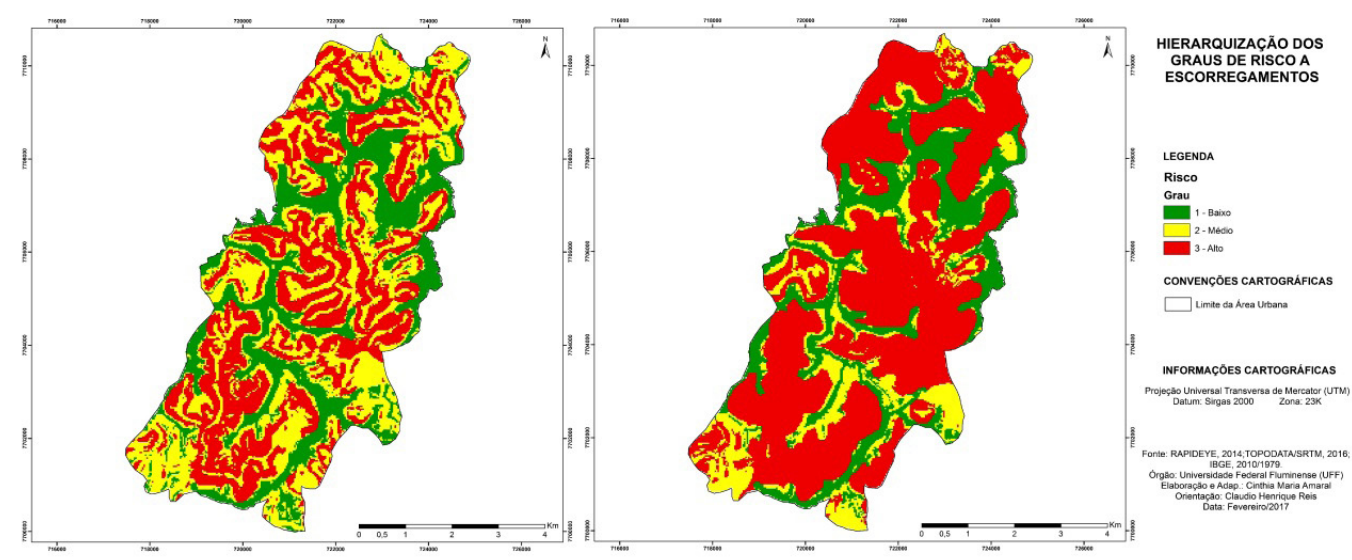

Fonte: Adaptado de Amaral, 2017.

Figura 6. Resultados da hierarquização de risco a inundações com aplicação da equação 1 e 2, respectivamente.

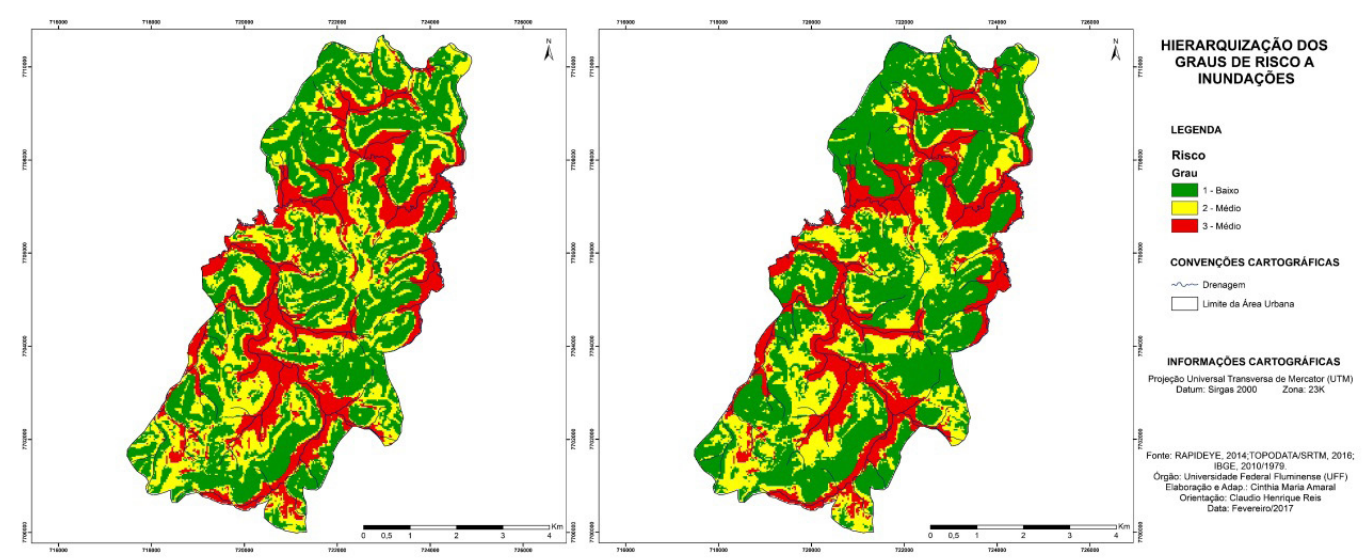


A ocorrência dos escorregamentos e inundações independem da presença ou interferência antrópica. Todavia, como ressaltado anteriormente, esses processos podem ser agravados e intensificados com o mau uso da terra e ocupação das áreas urbanas. Ademais, as caraterísticas físicas do relevo compactuam diretamente para a frequência dos processos pesquisados.

Destaca-se que a maior parte da área urbana do município de Viçosa possui declividade superior a $15 \%$ e, mais da metade, é formada por morros e com amplitudes altimétricas maiores que 100 metros. Desse modo, 62,28\% da área urbana é de Alto Risco (Grau 3) a escorregamentos. Seguido de 16\% com Médio Risco (Grau 2) e 21,14\% com Baixo Risco (Grau 1).

As áreas mais planas, com declividades inferiores a 15\%, são menos frequentes em sítio urbano, mas apresentam na sua configuração geomorfológica, planícies e terraços fluviais, que são as áreas mais suscetíveis a inundações. Para Alto Risco (Grau 3) de risco a inundações, a área representada é de 24,11\%, seguida pela de Médio Risco (Grau 2) com $25,25 \%$ e Baixo Risco (Grau 1) com a maior parcela, cerca de 50,64\%. Resultados estes justificados pela baixa presença de áreas planas. A Tabela 4 mostra os resultados obtidos, em área (valores absolutos e em porcentagens), da hierarquização dos graus riscos a escorregamentos e inundações.

Tabela 4. Total em área $\left(\mathrm{Km}^{2}\right)$ para os graus de hierarquização dos risco

\begin{tabular}{|c|c|c|c|}
\hline Grau & Risco & Área $\left(\mathrm{km}^{2}\right)$ Absoluto & Área $\left(\mathrm{km}^{2}\right) \%$ \\
\hline \multicolumn{4}{|c|}{ ESCORREGAMENTOS } \\
\hline 1 & Baixo & 8,79 & 21,14 \\
\hline 2 & Médio & 6,89 & 16,58 \\
\hline 3 & Alto & 25,9 & 62,28 \\
\hline \multicolumn{4}{|c|}{ INUNDAÇÕES } \\
\hline 1 & Baixo & 21,06 & 50,64 \\
\hline 2 & Médio & 10,5 & 25,25 \\
\hline 3 & Alto & 10,03 & 24,11 \\
\hline $\begin{array}{l}\text { Área Total } \\
\text { Analisada }\end{array}$ & - & 41,59 & 100 \\
\hline
\end{tabular}

Fonte: Adaptado de Amaral, 2017. 
Os mapas de riscos a escorregamentos (Figura 7) e riscos a inundações (Figura 8), mostram como se distribuem na área urbana do município de Viçosa. As áreas de riscos a escorregamentos de Grau 3, visivelmente detém a maior parcela do território e coincidem com as áreas mais declivosas e constituintes de morros. As áreas de riscos a inundação de Grau 3 estão concentradas próximos ao cursos d’água, principalmente nas drenagens mais expressivas como o rio Turvo Sujo, ribeirão São Bartolomeu e córrego da Conceição, estes dois últimos localizados na área urbana central.

Os escorregamentos são processos muito frequentes na área em estudo, principalmente em períodos de maior volume pluviométrico, mas, ressalta-se que para ocorrerem independem da ação da água. Outros problemas podem encadear esse processo, como retirada dos sopés das encostas, problemas na rede de drenagem, saturação do solo por ordem antrópica, etc. Dos tipos de escorregamentos existentes, translacional e rotacional (FERNANDES; AMARAL, 2009), o rotacional é o mais frequente. Em campo é possível verificar cicatrizes desses escorregamentos, bem como locais onde há maior suscetibilidade para ocorrerem.

\section{Figura 7. Hierarquização dos graus de risco a escorregamentos na área urbana}

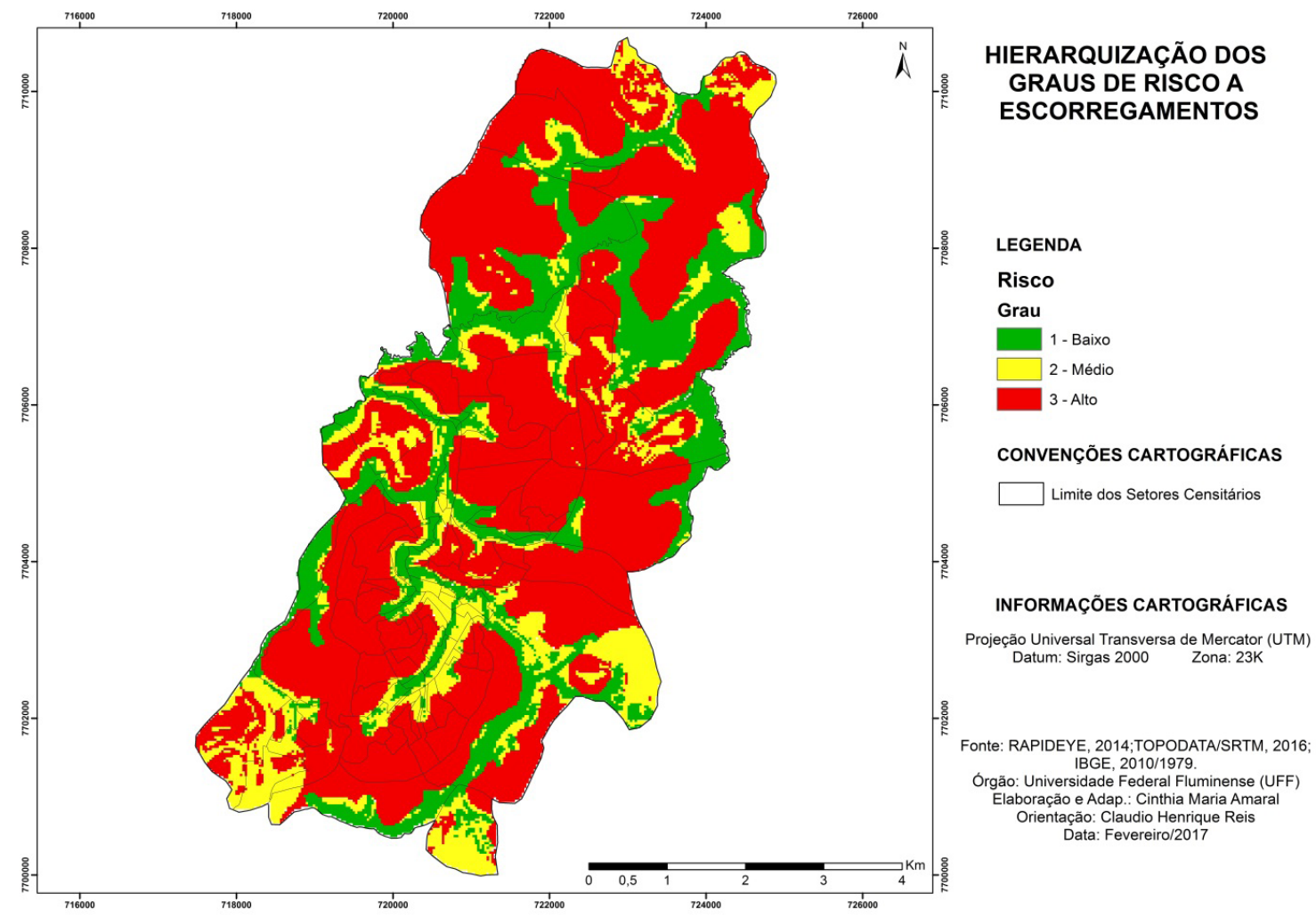

Fonte: Adaptado de Amaral, 2017. 
Figura 8. Hierarquização dos graus de risco a inundações na área urbana

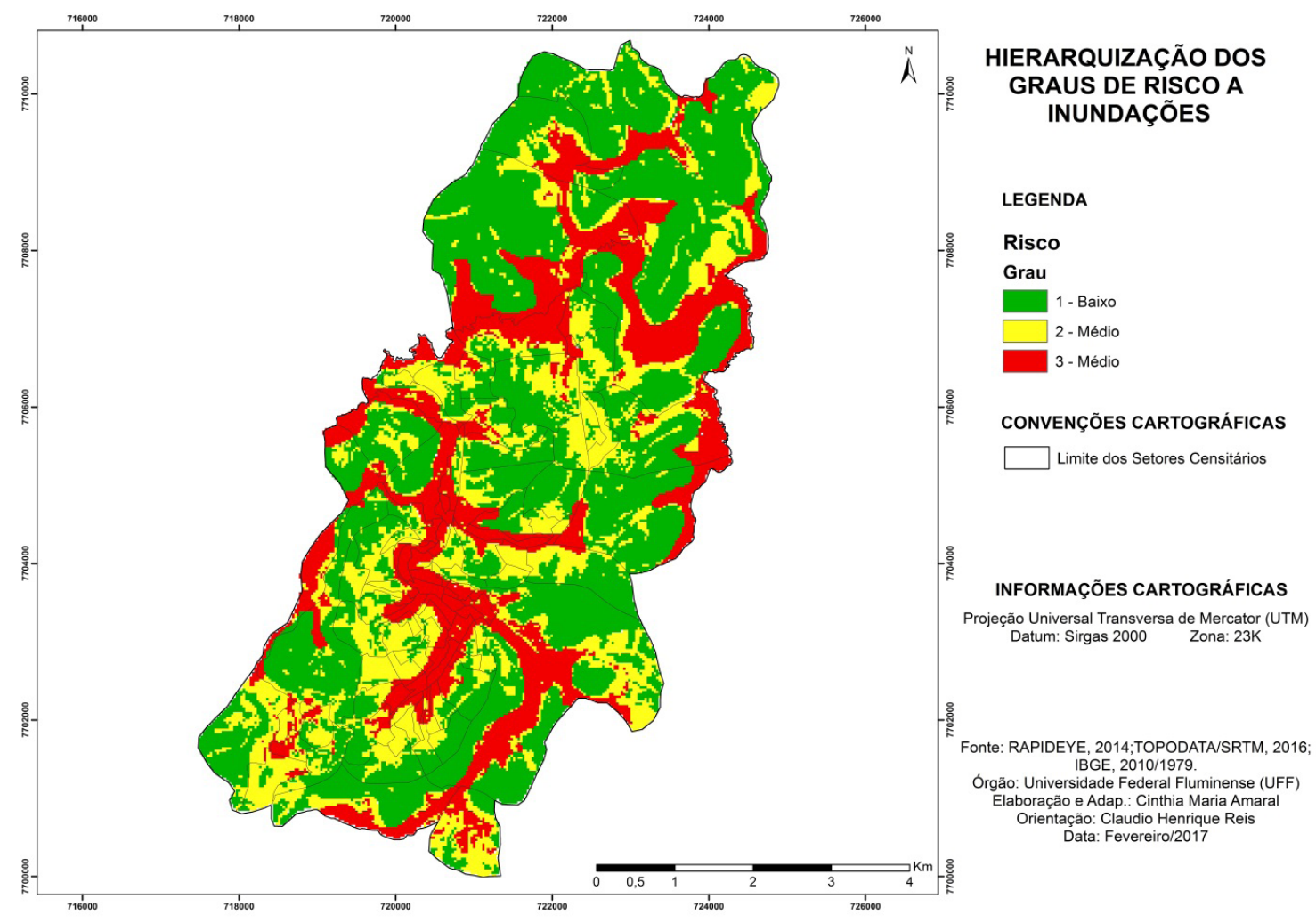

Fonte: Adaptado de Amaral, 2017.

As inundações do tipo bruscas (GOERL; KOBIYAMA, 2005) são as que mais ocorrem na região e se dão devido ao grande volume de chuva $(\mathrm{mm})$ em relação ao curto espaço de tempo (min/hora). Esses eventos também estão concentrados nos meses de maior volume pluviométrico, mas podem ocorrer, esporadicamente, em outras ocasiões. Além do processo de inundação, de ordem natural, outros problemas, de ordem induzida, ocorrem devido à impermeabilização do solo e rápido escoamento superficial como os alagamentos que são originados devido a má condição do sistema de drenagem, principalmente da captação pluvial.

\section{CONSIDERAÇÕES FINAIS}

A identificação e análise de áreas de riscos é um estudo imprescindível para auxílio ao planejamento e gestão pública, já que os escorregamentos e inundações estão propícios a ocorrer com maior frequência, mesmo estes sendo de ordem natural, em áreas degradadas com interferência antrópica acentuada. 
A área urbana de Viçosa se configura em relevo de vales mais encaixados, exutórios mais estreitos, entre médias e altas declividades, superiores a 15\%, com predominância de morros e amplitudes altimétricas superiores a 100 metros. As áreas próximas aos cursos d'água, declividade inferior a 15\%, estão demasiadamente ocupadas e, atualmente, esse processo de instalação urbana, por vezes, irregular, ramifica-se pelas encostas.

O mapeamento de risco a escorregamentos apontou que 62,28\% da área urbana é considerada de Alto Risco (Grau 3). As áreas de Baixo Risco (Grau 1) apresentam 21,14\% e as de Médio Risco (Grau 2), 16,58\% dessas áreas. Para o mapeamento de risco as inundações, 24,11\% representam as áreas de Alto Risco (Grau 3), 25,25\% as áreas de Médio Risco (Grau 2) e, 50,64\% as áreas de Baixo Risco (Grau 1).

A aplicação dessa metodologia mostrou-se viável e com resultados satisfatórios para a realidade da área em estudo e possível de ser aplicada e adaptada para outras realidades, além do baixo custo de execução. Os campos são importantes e imprescindíveis, pois permitem uma análise mais aguçada das temáticas envolvidas e de acordo com cada especificidade e, concomitante com os SIGs, possui um teor mais sistemático e ágil para coleta de dados.

\section{REFERÊNCIAS}

1. AGUIAR, O. B. M.; TEIXEIRA, H. M. Espécies florestais da mata atlântica: Usos e ocorrência na bacia hidrográfica do ribeirão São Bartolomeu, Viçosa-MG. In: Cadernos de Agroecologia - ISSN 2236-7934 - Vol. 10, No 3 de 2015. Disponível em: http://www.aba-agroecologia.org. br/revistas/index.php/cad/article/view/17959 . Acesso em: 18 jul. 2016.

2. AMARAL, C. M. Análise da fragilidade ambiental da bacia hidrográfica do córrego Matirumbide em Juiz de Fora-MG. Juiz de Fora, 2013. 88 f. Monografia de Conclusão de Curso (Graduação) - Curso de Geografia da Universidade Federal de Juiz de Fora. Juiz de Fora, 2013.

3. .Áreas de risco e vulnerabilidade social em áreas urbanas: soluções de mapeamento com técnicas de geotecnologias para viçosa-MG .Campos dos Goytacazes, 2017. 114 f. Dissertação de mestrado - Pós Graduação em Geografia da Universidade Federal Fluminense - UFF Campos. Campos dos Goytacazes, 2017.

4. BATISTA, M. S.; RODRIGUES, R. A. Análise climática de Viçosa associada á ocorrência de eventos pluviométricos extremos. Caminhos de Geografia, Instituto de Geografia - ufu, v. 11, n.36, p. 52 - 67, dez. 2010. Disponível em <www.ig.ufu.br/caminhosdegeografia. html> acesso em: 18 jul. 2016.

5. CARNEIRO, P. A. S.; FARIA, A. L. L. Ocupação de encostas e legislação urbanística em Viçosa (MG). Caminhos de Geografia. Uberlândia 12(14)121-138, Fev/2005. Disponível em: www.seer.ufu. br/index.php/caminhosdegeografia/article/download/15376/8675. Acesso em 04 de jan. de 2017. 
6. CORDEIRO, J. P.; BARBOSA, C. C. F.; CAMARA, G. Álgebra de Campos e Objetos. In: CAMARA, G; DAVIS, C.; MONTEIRO, A.M.V. Introdução à Ciência da Geoinformação. INPE, São José dos Campos, 2001. Disponível em: http://mtc-m12.sid.inpe.br/col/sid.inpe. br/sergio/2004/04.22.07.43/doc/publicacao.pdf. Acesso em: 25 mai. 2016.

7. DPI - INPE. Departamento de Processamento de Imagens - Instituto Nacional de Pesquisas Espaciais. Tutorial de Geoprocessamento. Disponível em: http://www.dpi.inpe.br/spring/ portugues/tutorial/index.html. Acesso em: 13 dez. 2015.

8. FERNANDES, N. F; AMARAL, C. P. Movimentos de Massa: Uma Abordagem GeológicoGeomorfológica. In: Geomorfologia e Meio Ambiente. GUERRA, A. J. T. e CUNHA, S. B. (orgs.). Editora Bertrand Brasil, Rio de Janeiro, $7^{\text {a }}$ ed. 2009. p. 123-194.

9. FLORENZANO, T. G. Sensoriamento remoto para geomorfologia. In: FLORENZANO, T. G. (org.). Geomorfologia: conceitos e tecnologias atuais. São Paulo: Oficina de Textos, 2008. p. 31 - 71.

10. GOERL, R. F.; KOBIYAMA, M. Considerações sobre as inundações no Brasil. Disponível em: http://www.labhidro.ufsc.br/Artigos/ABRH2005_inundacoes.pdf. Acesso em: 29 jul. 2016.

11. GONÇALVES, L. F. H.; GUERRA, A. J. T. Movimentos de massa na cidade de Petrópolis (Rio de Janeiro). In: CUNHA, S. B; GUERRA, A. J. T. (orgs.). Impactos ambientais urbanos no Brasil.

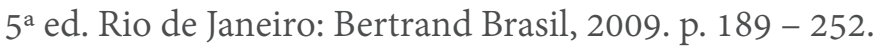

12. GUERRA, A. J. T.; MARÇAL, M. S. Geomorfologia ambiental. $7^{\text {a }}$ ed. - Rio de Janeiro: Bertrand Brasil, 2015. $192 \mathrm{p}$.

13. GUIMARÃES, R. F.; CARVALHO JÚNIOR, O. A. de.; GOMES, R. A. T.; FERNANDES, N. F. Movimentos de massa. In: FLORENZANO, T. G. (org.). Geomorfologia: conceitos e tecnologias atuais. São Paulo: Oficina de Textos, 2008. p. 159 - 184.

14. IBGE - Instituto Brasileiro de Geografia e Estatística . Manual Técnico de Geomorfologia. $2^{\mathrm{a}}$ ed. - Rio de Janeiro: IBGE, 2009. 175 p.

15. . Censo Demográfico 2010. Características da População. Rio de Janeiro: IBGE, 2010.

16. IPT - Instituto de Pesquisas Tecnológicas do Estado de São Paulo. Mapa geomorfológico do Estado de São Paulo. Divisão de Minas e Geologia Aplicada. São Paulo, 1981. 94 p.

17. JORGE, M. C. O.; GUERRA, A. J. T. Erosão dos solos e movimentos de massa - recuperação de áreas degradadas com técnicas de bioengenharia e prevenção de acidentes. In: GUERRA, A. J. T.; JORGE, M. C. O (Orgs.). Processos erosivos e recuperação de áreas degradadas. São Paulo: Oficina de Textos, 2013. 192 p.

18. KOBIYAMA, M.; MENDONÇA, M.; MORENO, D. A.; MARCELINO, I. P. V. O.; MARCELINO, E. V.; GONÇALVES, E. F.; BRAZETTI, L. L. P.; GOERL, R. F.; MOLLERI, G. S. F. RUDORFF, F.M. Prevenção de Desastres Naturais: Conceitos Básicos. $1^{\text {a }}$ ed. Editora: Organic Trading. Curitiba, 2006. 109 p. 
19. MINISTÉRIO DAS CIDADES - IPT. Instituto de Pesquisas Tecnológicas. Mapeamento de riscos em encostas e margens de rios. Brasília: Ministério das Cidades. Instituto de Pesquisas Tecnológicas - IPT, 2007. 176 p. Disponível em: http://www.cidades.gov.br/images/stories/ ArquivosSNPU/Biblioteca/PrevencaoErradicacao/Livro_Mapeamento_Enconstas_Margens. pdf. Acesso em: 29 jul. 2016.

20. PREFEITURA DE VIÇOSA. O território. Disponível em http://www.vicosa.mg.gov.br/acidade/territorio. Acesso em: 06 jun. 2016.

21. ROQUE, L. A. Áreas de risco geológico-geotécnico associadas a movimentos de massa no núcleo urbano de Viçosa-MG. 97 f. - Viçosa, MG, 2013. Dissertação (mestrado) - Universidade Federal de Viçosa.

22. ROSA, R. Introdução ao Sensoriamento Remoto. $7^{\text {a }}$ ed. - Uberlândia: EDUFU, 2009. 260 p.

23. REZENDE, S. B. Estudo de crono-topossequência em Viçosa - Minas Gerais. Departamento de Solos / UFV, Dissertação de Mestrado. Viçosa, 1971, 71 p.

24. ROSS, J. L. S. O registro cartográfico dos fatos geomórficos e a questão da taxonomia do relevo. In: Revista do Departamento de Geografia n. 6, p. 17-29. São Paulo, 1992.

25. SAITO, S. M.; SORIANO, E.; LONDE, L. R. Desastres Naturais. In: SAUSEN, T. M.; LACRUZ, M. S. P. (Org.). Sensoriamento Remoto para Desastres. - - São Paulo: Oficina de Textos, 2015. p. 23-42.

26. SANTOS, A.R. dos; PELUZIO, T.M. de;SAITO, N. S. Spring 5.1.2 - Passo a Passo. Aplicações Práticas. Mundo da Geomática, Alegre, 2010.155 p. Disponível em: http://www.mundogeomatica.com.br/ Livros/Livro_Spring_5.1.2_Aplicacoes_Praticas/LivroSPRING512PassoaPassoAplicacaoPratica. pdf. Acesso em: 12 ago. 2016.

27. SILVEIRA, A.; CUNHA, C. M . L. da. A influência da declividade nos processos erosivos na bacia do Tijuco Preto-SP. In: VI Simpósio Nacional de Geomorfologia (SINAGEO), 2006, Goiania. Anais... Goiania, 2006. Disponível em: http://www.labogef.iesa.ufg.br/links/sinageo/ articles/110.pdf. Acesso em 06 abr. 2017.

28. TORRES, F. T. P. MARQUES NETO, R; MENEZES, S. O. Introdução à geomorfologia. São Paulo: Cengage Learning, 2012. 322p.

29. TUCCI, C. M. Inundações Urbanas. - Porto Alegre: ABRH/RHAMA, 2007. 393 p.

30. VALVERDE, O. Estudo regional da Zona da Mata de Minas Gerais. Revista Brasileira de Geografia, IBGE: v.20, n 1, 1958.

ARTIGO RECEBIDO EM ABRIL DE 2017

ARTIGO APROVADO EM AGOSTO DE 2017 